بررسى ارتباط ماهيان كور غار لرستان (Garra lorestanensis و و و جمعيتهاى ماهى كلجر اغ (Garra gymnothorax) در حوضههاي دز و كرخه

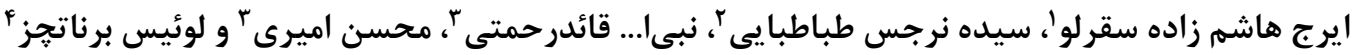

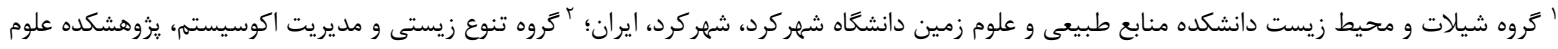

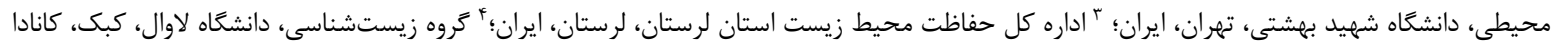

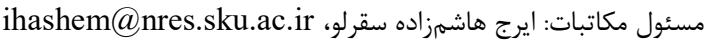

קكيده. غار محل زيست ماهيان كور لرستان در حوضه رود دز در مجاورت رودخانه سزار در منطقهاى با ساختار كارستى قرار گرفته است. در مجاورت رودخانه

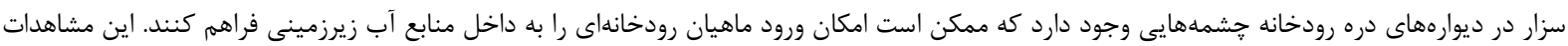

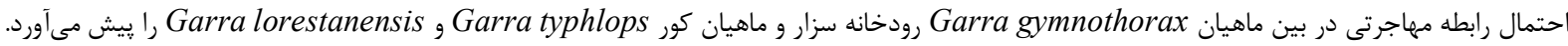

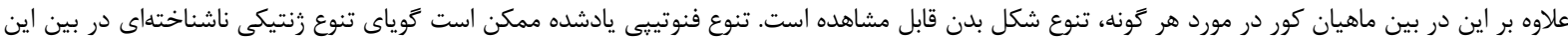

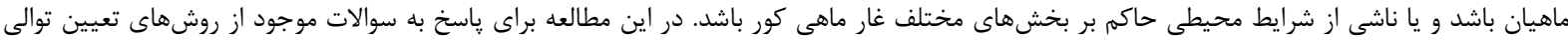

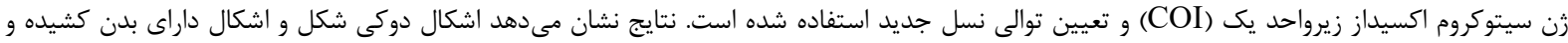

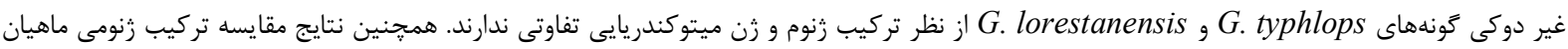

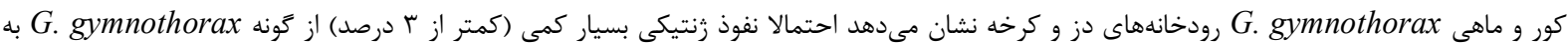

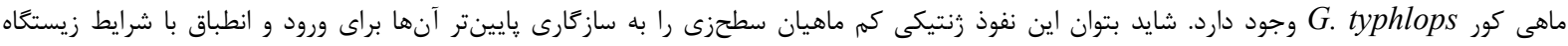
زيرزمينى نسبت داد. وازههاى كليدى. تركيب زنوم، تنوع شكل، توالى يابى نسل جديد، زنوم ميتوكندريايى، غار ماهى كور

\title{
The analysis of the relationship between Lorestan cave barbs (Garra typhlops and Garra lorestanensis) and Garra gymnothorax populations in Dez and Karkheh River drainages
}

\section{Iraj Hashemzadeh Segherloo ${ }^{1}$, Seyedeh Narjes Tabatabaei ${ }^{2}$, Nabiallah Ghaed Rahmati ${ }^{3}$, Mohsen Amiri ${ }^{3}$ \& Louis Bernatchez ${ }^{4}$}

${ }^{1}$ Department of Fisheries and Environmental Sciences, Faculty of Natural Resources and Earth Sciences, Shahr-e-Kord University, Shahr-e-Kord, Iran; ${ }^{2}$ Department of Biodiversity and Ecosystem Management, Environmental sciences Research Institute, Shahid Beheshti University, Tehran, Iran; ${ }^{3}$ Lorestan Province Department of Environment, Khoramabad, Iran; ${ }^{4}$ Department of Biology, Laval University, Quebec, Canada

Correspondent author: Iraj Hashemzadeh Segherloo, ihashem@sku.ac.ir

\begin{abstract}
The cave barb habitat is located in a Karst formation along the Sezar River. The springs on the walls of the Sezar River valley may provide a means for fish in surface waters to penetrate into the underground waters. These observations propose the probability for a migratory relationship between Garra gymnothorax in the Sezar River and the cave barbs (Garra typhlops and Garra lorestanensis). In addition, a variety of different body shapes including fusiform and slender body forms are observed among the cave fish. This phenotypical variation may be a sign of an unknown genetic diversity or could be attributed to the variable environmental conditions in different parts of the subterranean habitat. To clarify the situation, we used the sequences of mtDNA cytochrome oxidase subunit I and next generation sequencing method. The results showed that the fusiform and slender body shapes of G. typhlops and $G$. lorestanensis were not different with regard to their mtDNA and genomic compositions. Moreover, the analysis of the genomic
\end{abstract}


their mtDNA and genomic compositions. Moreover, the analysis of the genomic showed that a limited level of gene flow (less than 3\%) from G. gymnothorax probably existed in G. thyphlops. The low level of gene flow may be related to the lower fitness and adaptability of the surface dwelling fish to the subterranean life conditions.

Key words. Cave barb locality, genome composition, mitochondrial genome, morphological diversity, next generation sequencing

يابى اين تفاوتها نيازمند انجام مطالعات بوم شناسى و زنتيكى دقيق است.

مطالعاتى كه تاكنون در مورد ماهيان كور غار لرستان انجام

شده است، شامل بررسى هاى ريختشناسى ( 2008; Mousavi-Sabet \& Eagderi, 2016 Farashi, ) زنتيك جمعيت با استفاده از نشانگرهاى ريزماهواره

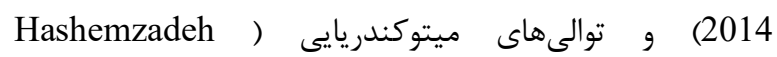
بوده (Segherloo et al., 2012a; Farashi et al., 2014 است. مطالعات ريختشناسى به دليل اثرات محيط بر ريخت ماهيان و تغييرات غيرزنتيكى نمىتوانند اطلاعات دقيقى در مورد

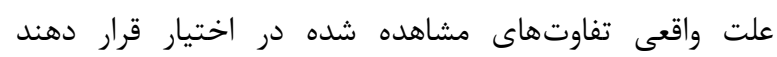
Hashemzadeh Segherloo et al., 2012b) مشاهدات به صورت دقيقتر و با كمترين تأثيريذيرى از عوامل

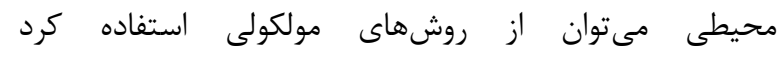

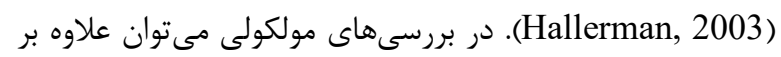

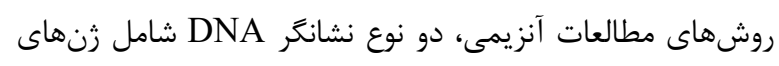
موجود در زنوم ميتوكندريايى (mtDNA) و زنهاى رونى هستهاى

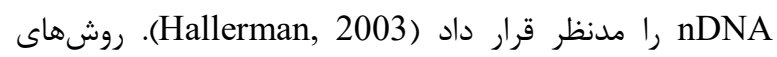
مطالعات آنزيمى به دليل ماهيت نمونهبردارىهاى بافتى كه

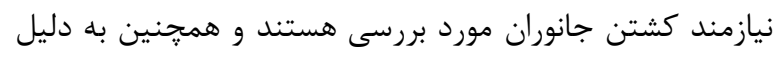

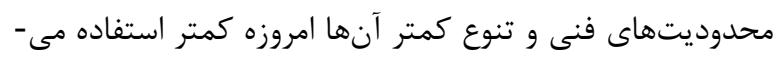
شوند (Dunham, 2011). زن هاى موجود در زنوم ميتوكندريايى به دليل وراثت تكوالدى تنهها مىتوانند زوياى تقويم و و رخدادهاى شجره مادرى باشند و اطلاعات خاصى را در مورد

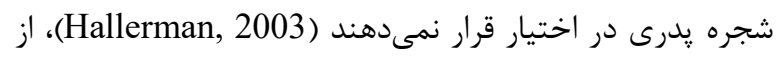

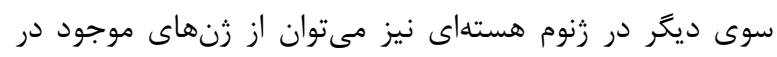

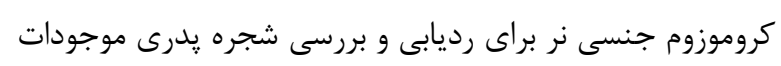

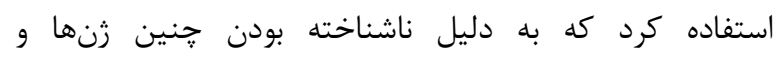
كروموزومهاى جنسى نر در اغلب ماهيان استفاده از اين رويكرد

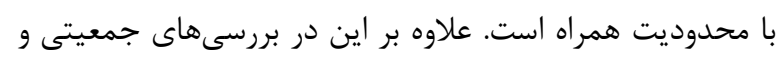
حتى شجرهشناسى اين زنها به دلايلى مثل تفاوت ضرايب نوتركيبى و جهش در قسمتهاى مختلف زنوم نمىتوانند معيار مناسبى براى مشاهدات بومشناختى باشند ( Hashemzadeh

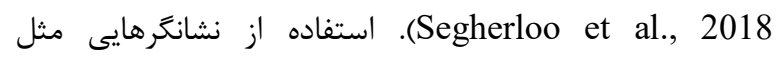
نشانگرهاى ريزماهواره در مطالعات جمعيتى و بومشناسى مىتواند
اولين زيستخاه شناسايى شده ماهيان كور ايران در منطقه يايى

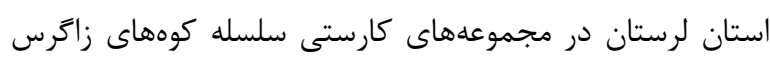
در مجاورت رودخانه دز به صورت خروجى يك غار قرار دارد (Hashemzadeh Segherloo et al., 2012a) سه Fونه ماهى كور شامل Garra typhlops، Eidinemacheilus smithii g lorestanensis Hashemzadeh Segherloo et al. 2016; Mousavi-) (Sabet \& Eagderi, 2016 ). سطح آب در اين زيستخاه در

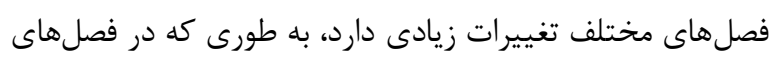

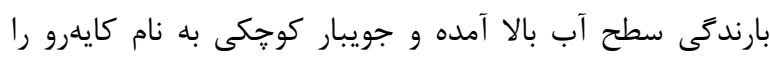

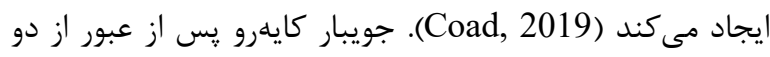

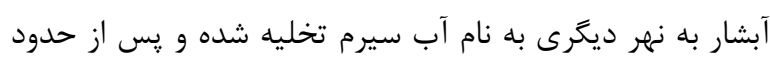

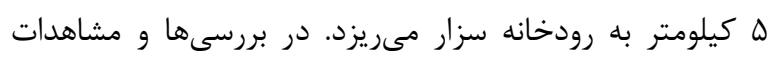

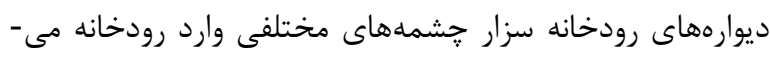

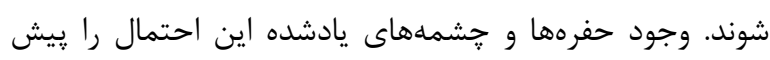

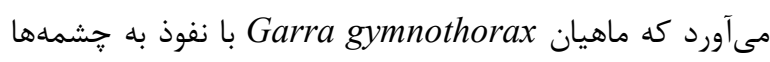
و حفرات موجود به زيستخاههاى زيرزمينى راه يافته و بان ماهي ماهيان كور Garra lorestanensis , Garra typhlops زنتيكى انجام دهند.

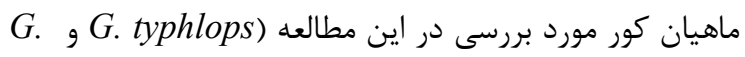
معمولا داراى بدن دوكى شكل، داراى رنى مطن (lorestanensis Sرمى-صورتى روشن و فاقد جشم هستند ( Sargeran et al., 2008). تفاوت ظاهرى ماهيان يادشده در وجود ديسك دهانى در در

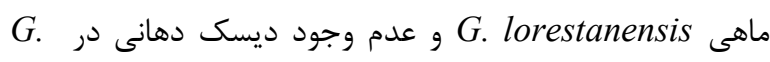
typhlops تفاوت در شكل دهان نوعى سازگارى با كنجهاى اكولوزيك

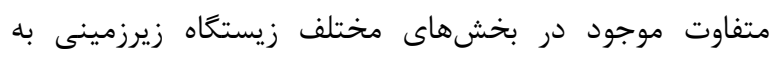

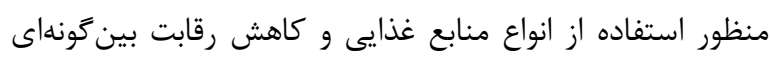
است (Hashemzadeh Segherloo et al., 2018). در بين إنغ ماهيان كور داراى بدن دوكى شكل نمونههايى مشاهده مىشود

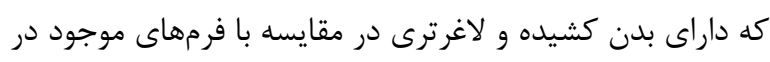

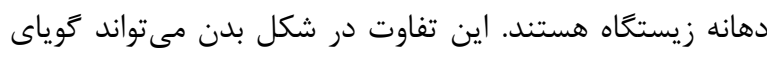
تفاوتهاى زنتيكى و يا تفاوتهاى بوم شناختى باشد كه ريشه - رين 
نمونهها، باله سينهاى آنها معمولا بعد از بيهوشى در محلول كل

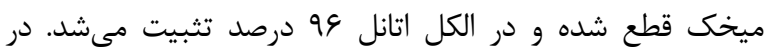

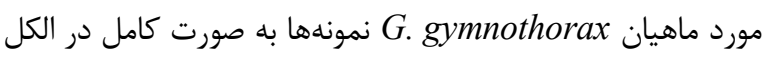
تثبيت مىشدند. نمونهای ماهيان كور بريايه وجود يا عدم وجود

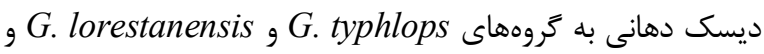

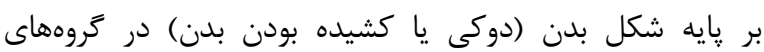

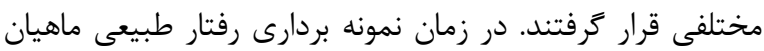

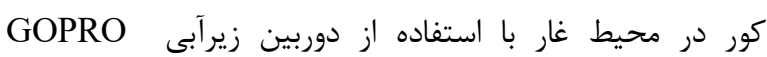
HERO2

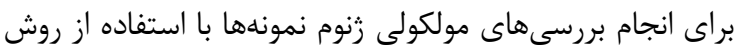

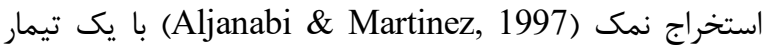
RNAse براى تجزيه RNA موجود در نمونه استخراج شد ندائ (Benestan et al., 2015) براى تعيين توالى نسل جديد از روش (Genotyping-by-Sequencing) GBS

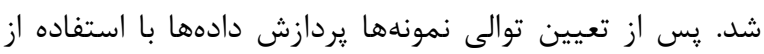

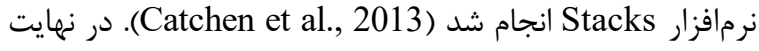

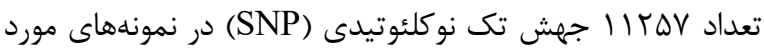

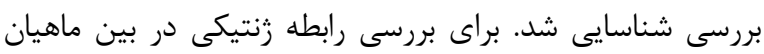
G. gymnothorax

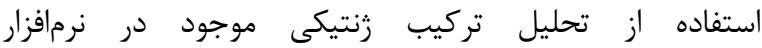

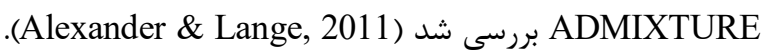
براى تعيين كروهبندى مناسب تركيبات زنتيكى مشاهده شده،

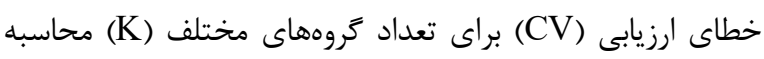

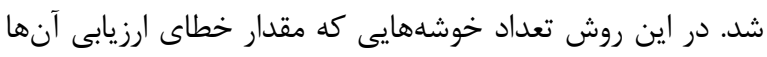
كمتر باشد به عنوان تعداد خوشههاى واقعى مدنظر قرار مئى رئيرند،

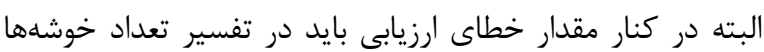

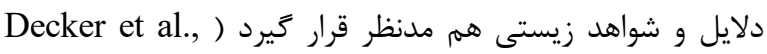

(2014 براى تكثير زن COI از يرايمرهاى FishF1 و FishR1 استفاده

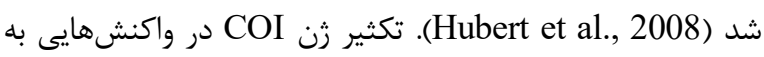
حجم •1 ميكروليتر با استفاده از هشت ميكروليتر ميكس آماده AccuStart II PCR SuperMix غلظت •ا ميكرومولار و يك ميكروليتر DNA انجام شد. عمليات

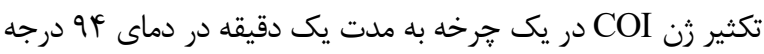

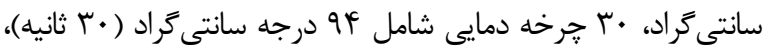

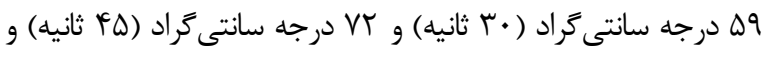

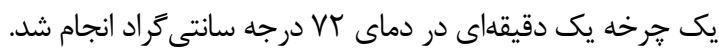

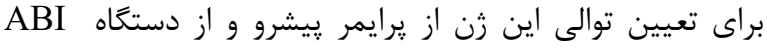

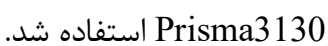

راهگشا باشد. اما اين روشها نيازمند در دست داشتن تعداد

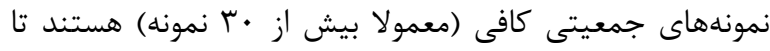

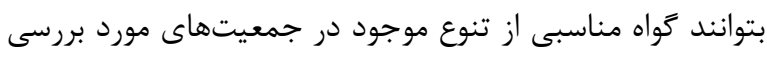
باشند. در مورد تونههاى در معرض خطر مثل ماهيان كور غار كه موند

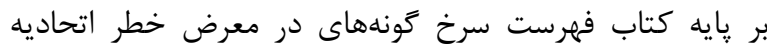

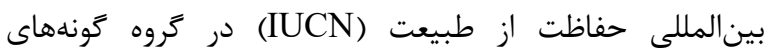
آسيبيذير (Vulnerable) قرار دارند، به دلايل حفاظتى و وإنى همجنين به علت محدوديت احتمالى اندازه جمعيت نمى إنوان

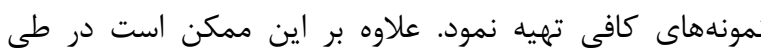

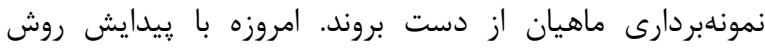

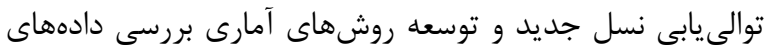

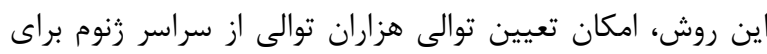
جندين فرد به طور همزمان و در يك واكنش فراهم شده است (Hashemzadeh Segherloo et al., 2018)

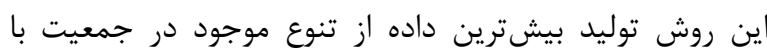

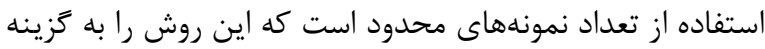

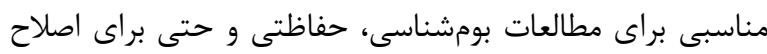

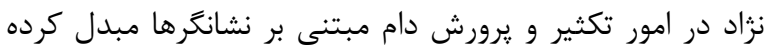
است (Decker et al., 2014).

يبرو مطالب يادشده در مورد كونههاى ماهيان كور، در اين

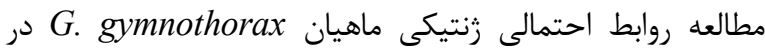
حوضههاى كرخه و دز با ماهيان كور G. G. Gyphlops lorestanensis

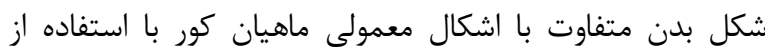
توالىيابى نسل جديد و همجنين با استفاده از توالى زن سيتوكروم

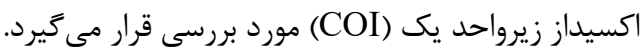

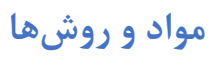

براى انجام اين مطالعه نمونه بردارىها در فروردين و ارديبهشت

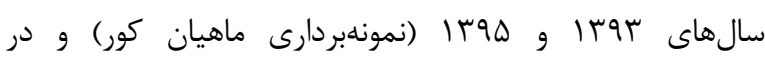
شهريورماه هوبا (نمونهبردارى ماهيان Gymnothorax حوضههاى كرخه و دز انجام شد. براى نمونه بردارى ماهيان كور از

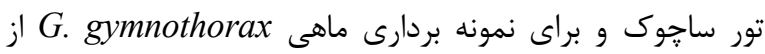
الكتروشوكر كول קشتى SAMUS استفاده شد. در اين مطالعه تعداد ينج قطعه ماهى G. lorestanensis، شش قطعه ماهى G. typhlops

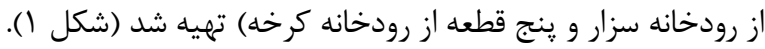

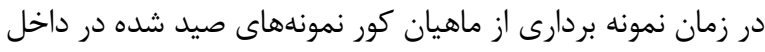

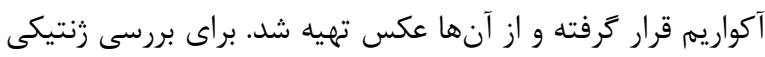




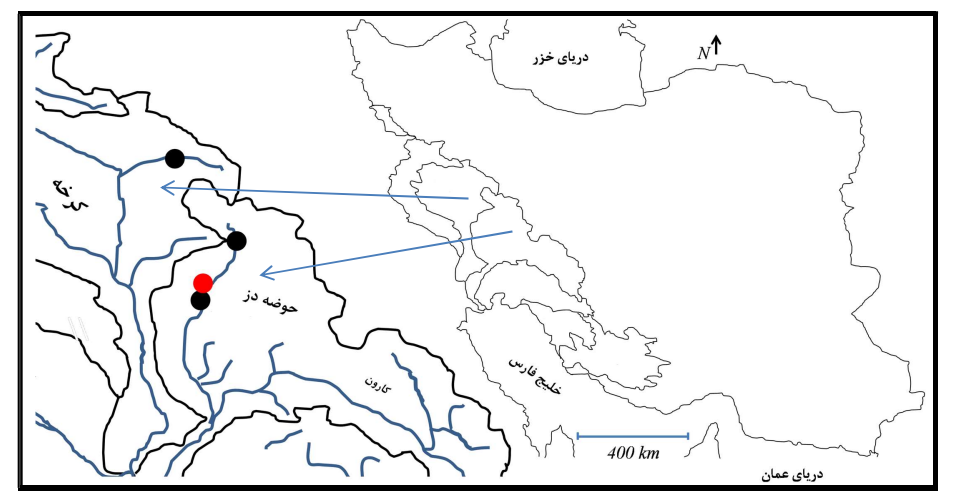

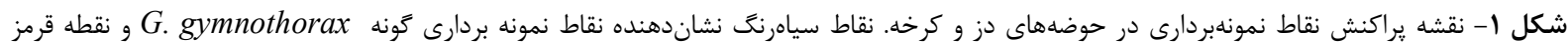
رنغ نشاندهنده محل غار ماهى كور است.

Fig. 1. Distribution map of sampling localities in the Dez and Karkheh River drainages. The black points denote the sampling localities for G. gymnothorax and the red point denotes the cave barb locality.

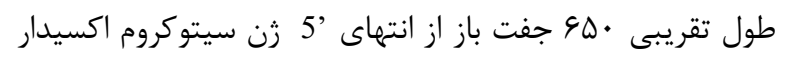

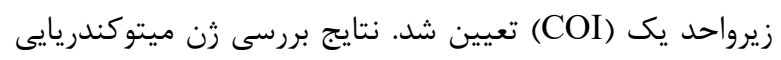

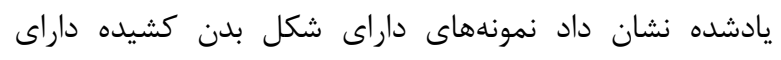

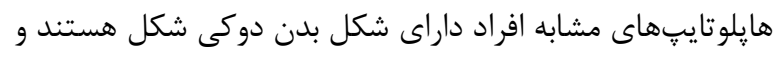

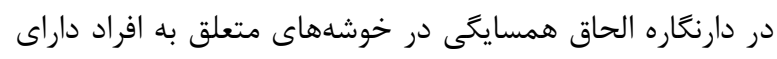

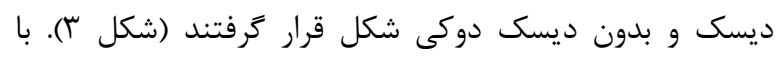

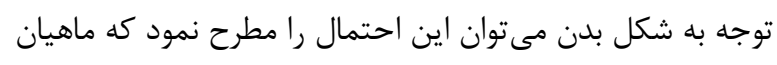

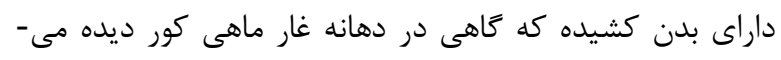

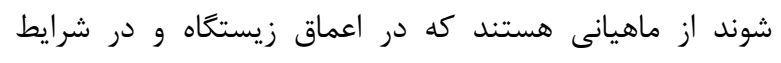

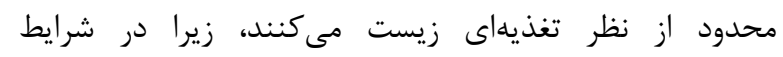

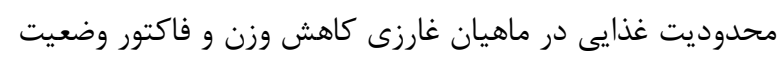

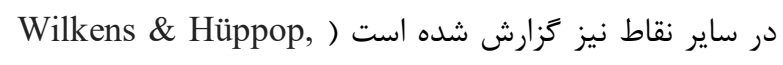

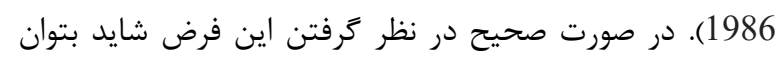
عنوان نمود كه هر دو كونه ماهيان كور در در اعماق زيستخاه

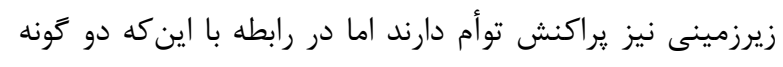

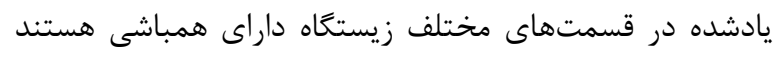

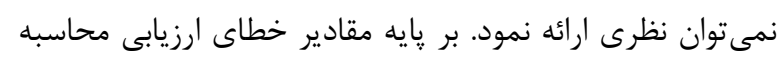

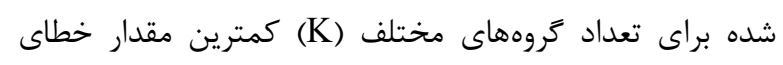

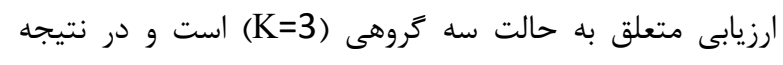

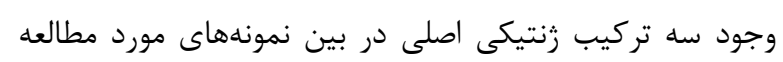

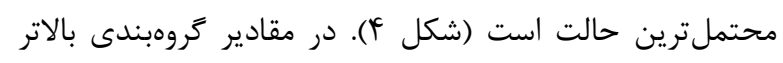

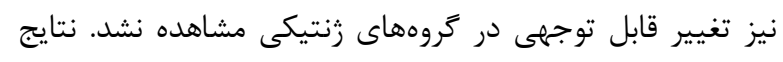

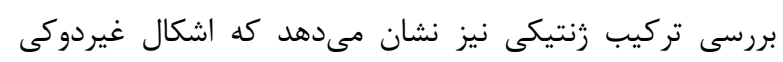

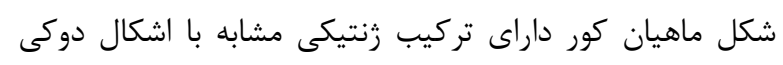

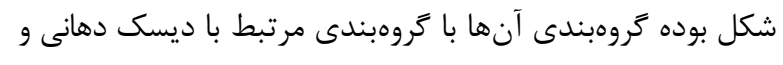

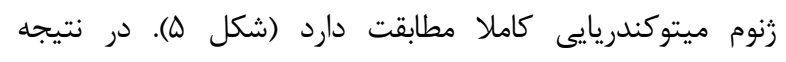

كيفيت توالىهاى به دست آمده با استفاده از نرم افزار Bioedit

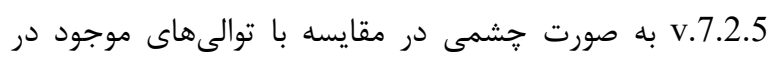

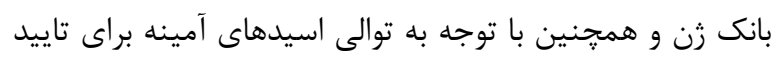

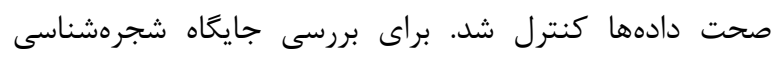

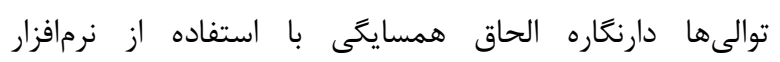

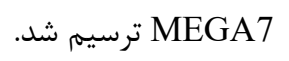

\section{نتايج و بحث}

در بين نمونههاى تهيه شده دو قطعه ماهى كور داراى بد بدن

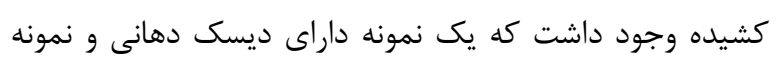

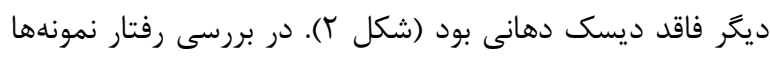

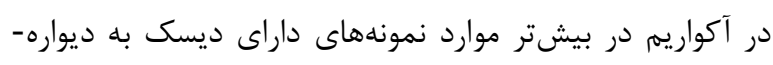

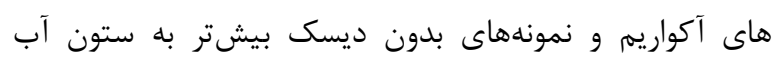

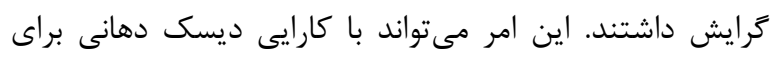

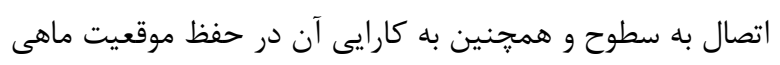

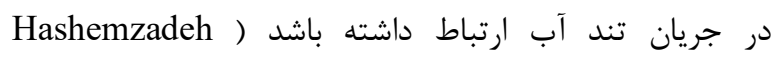

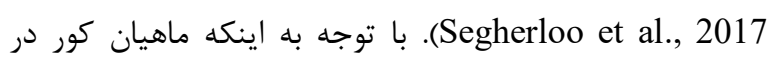

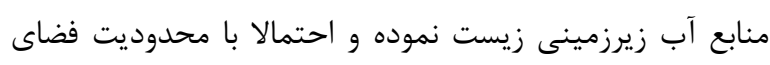

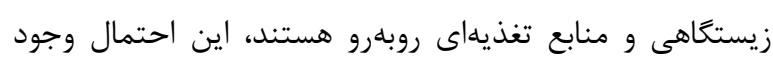

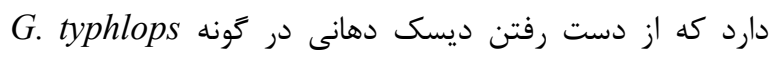

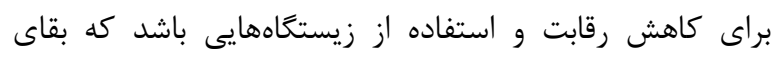

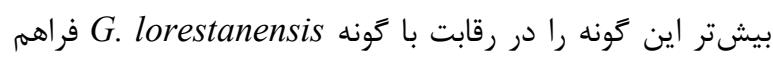

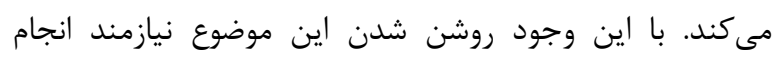

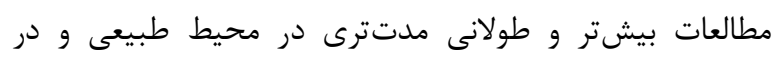

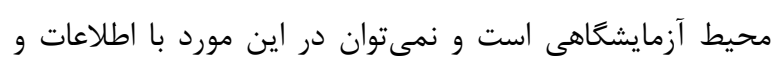

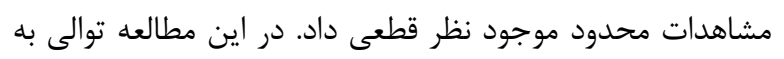




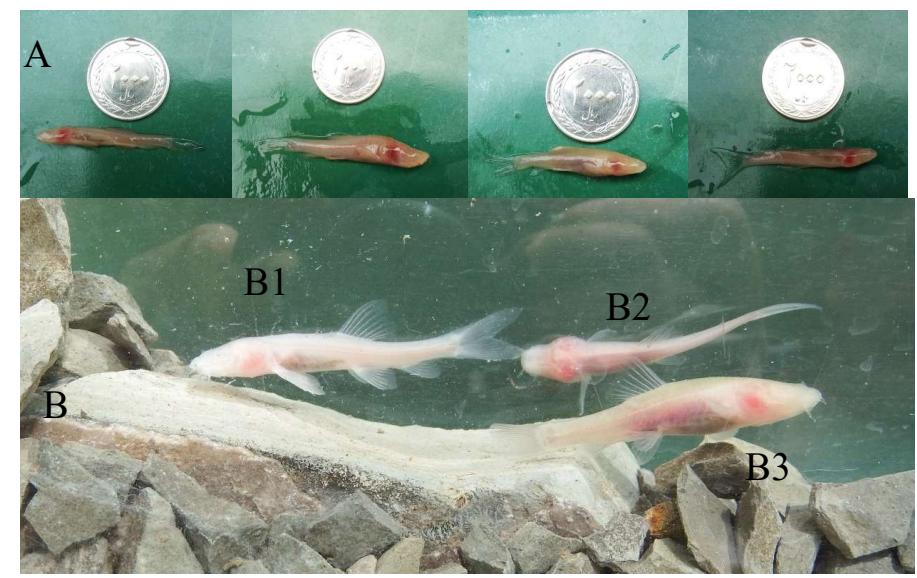

شكل r- تصاوير اشكال كشيده و دوكى شكل بدن ماهى كور. A. از راست به جٍٍ: فرم كشيده بدون ديسك، فرم بدون ديسك دوكى شكل، فرم بدون ديسك با

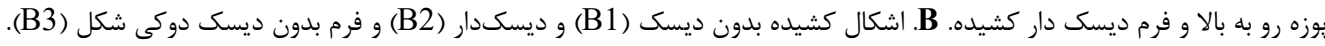

Fig. 2. Fusiform and slender body shapes of the Blind Cave barb. A. From right to left: slender non-disc form, fusiform non-disc form, non-disc form with oblique snout, and disc bearing form with a slender body shape. B. the non-disc (B1) and disc bearing cave barbs with slender body form (B2) and the non-disc form with a fusiform body shape (B3).
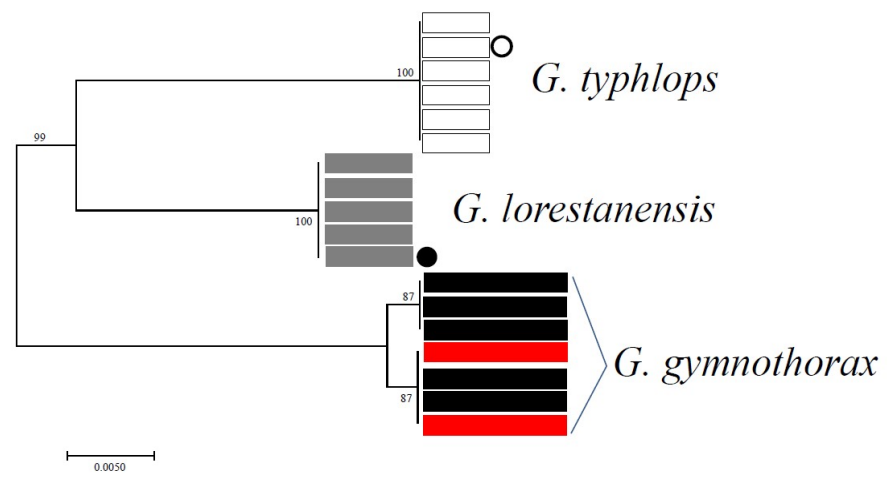

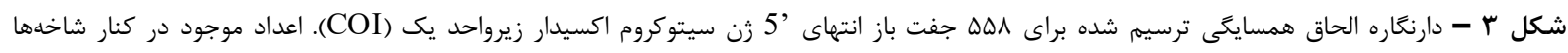

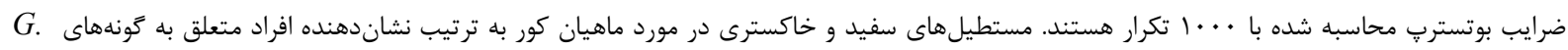
Gymnothorax Gy lorestanensis و typhlops

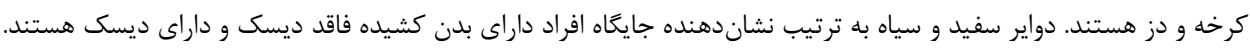

Fig. 3. Neighbour-Joining phylogram reconstructed for a 558 bp 5 ' end of Cytochrome oxidase subunit I (COI).The values beside the branches are bootstrap supports calculated using 1000 bootstrap replicates. The white and gray rectangles denote $G$. typhlops and $G$. lorestanensis individuals, respectively; and the black and red rectangles denote $G$. gymnothorax individuals from Karkheh and Dez Rivers, respectively.

جمعيتى نزديك آنها و يا منشأ مشترك آنها در كذشته نزديك

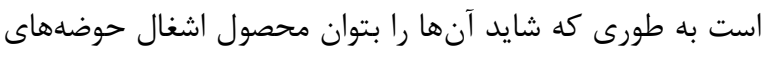

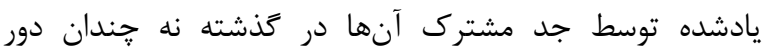
دانست. تاييد اين فرض نيازمند مطالعات بيشتر و تهبيه نقشه دقيقترى از يراكنش جمعتهاى اين گونه و روابط زينتيكى آنها است. برخلاف جمعيتهاى ماهى Gymnothorax. كور در يك زيستخاه و داراى دو تركيب زنتيكى متفاوت هستند

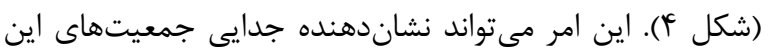

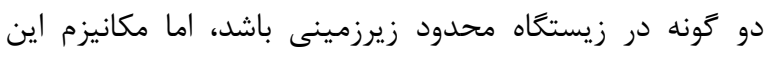
جدايى جندان روشن نيست. با توجه به اينكه دو گونه يادشده در
نمىتوان شكل بدن غيردوكى را به تركيب زنتيكى نسبت داد و

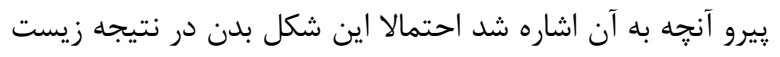

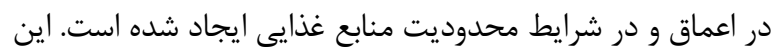

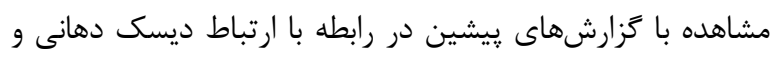
وضعيت ردهبندى ماهيان كور مطابقت دارد ( Hashemzadeh .(Segherloo et al., 2012a; Farashi et al., 2014 نتايج بررسى تركيب زنتيكى همجنين تفاوتى را در بين نمونههاى G. gymnothorax علاوه بر يكسان بودن وضعيت شجرهشناسى ميتوكندريايى (شكل

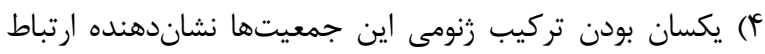




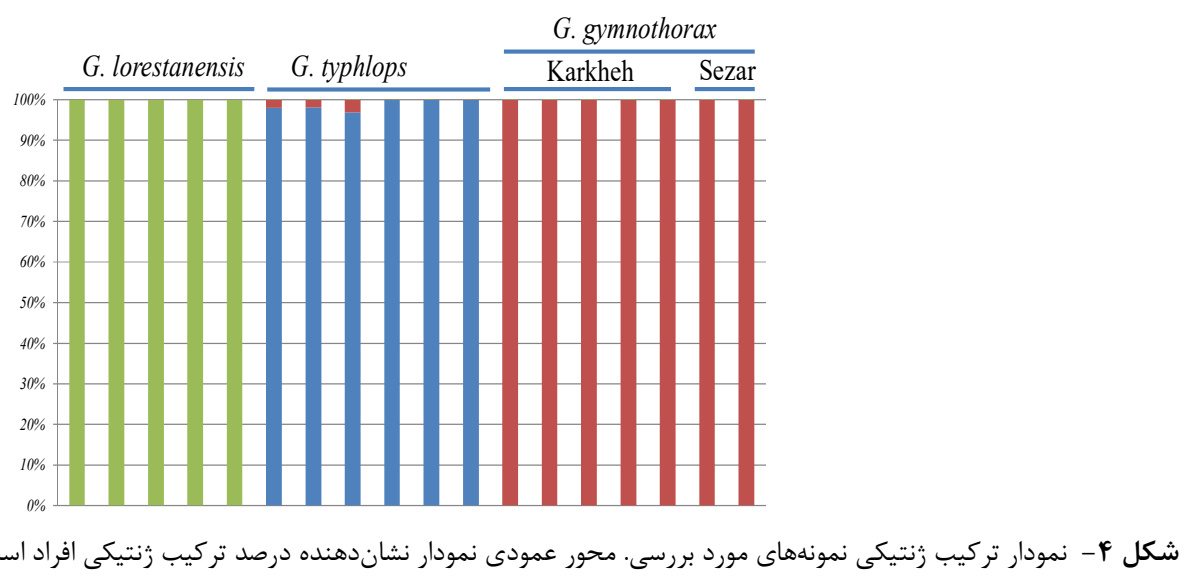

Fig. 4. Admixture graph of the analyzed specimens. The vertical bars denote the percentage of ancestry of each individual.

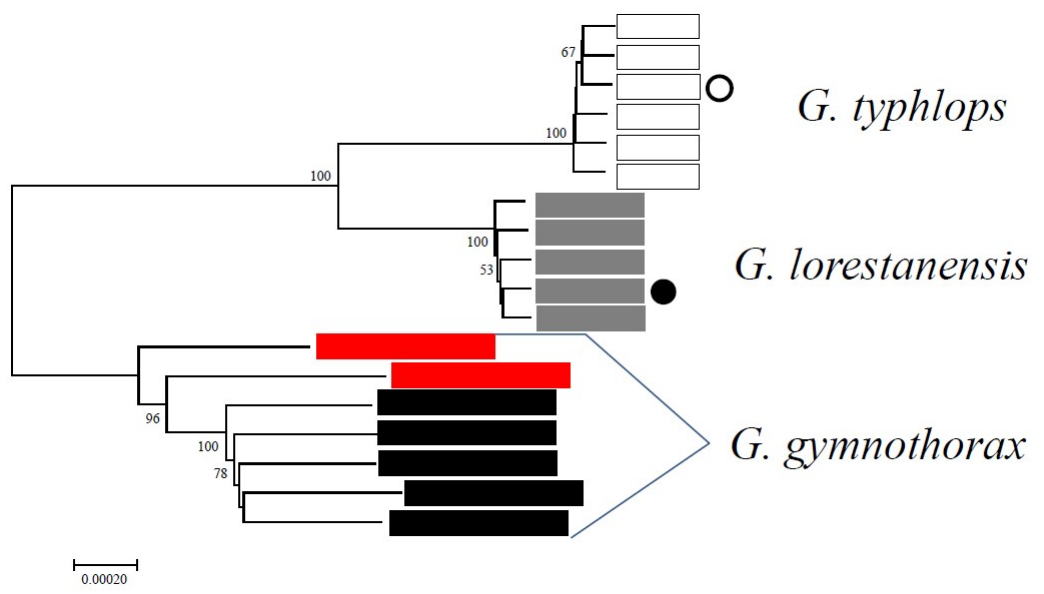

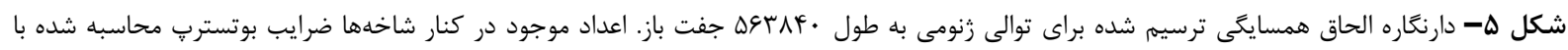

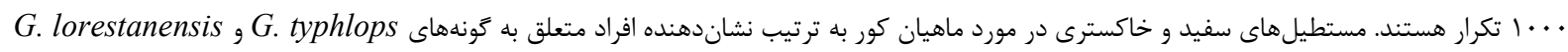

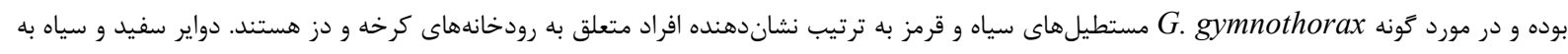

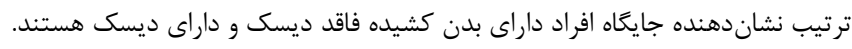

Fig. 5. Neighbour-Joining phylogram reconstructed for a 563840 bp concatenated genomic sequence. The values beside the branches are bootstrap supports calculated using 1000 bootstrap replicates. The white and gray rectangles denote $G$. typhlops and G. lorestanensis individuals, respectively; and the black and red rectangles denote G. gymnothorax individuals from Karkheh and Dez Rivers, respectively.

موضوع نشاندهنده نوعى ارتباط زنتيكى محدود در بين جمعيتهاى رودخانهاى و زيستخاه زيرزمينى است. البته با توجه به درصد بسيار كم اين تركيبات نمىتوان اين حالت را اتفاقى

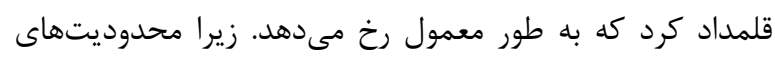
بسيارى براى ورود ماهيان از زيستخاه رودخانهاى به زيستخاه

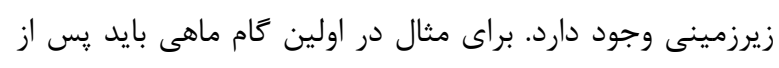

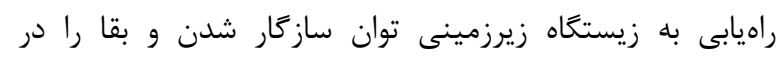

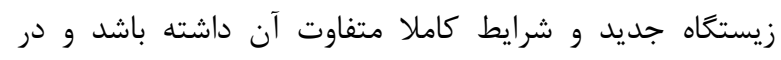
صورت موفقيت بايد با گونههاى ساكن زيستخاه زيرزمينى داراى

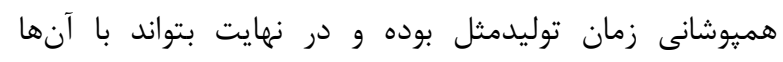

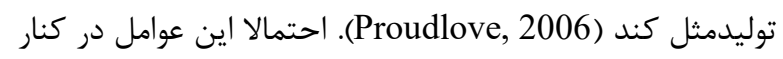

زمان مشابه در زيستگاه و در نقطه يكسانى نمونهبردارى شدهاند

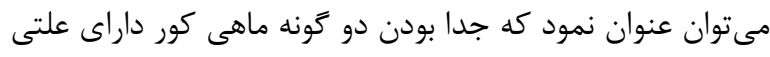

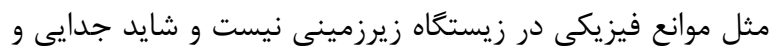

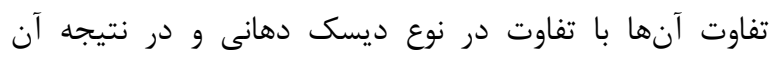
تفاوتهاى بوم شناختى باشد. اين قضاوتها نيز با توجه بله عدم

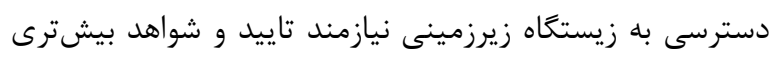

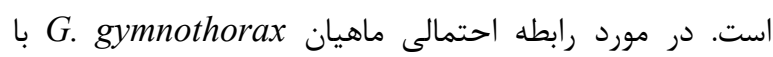
ماهيان كور از طريق ساختارهاى كارستى منطقه در نمودار G. typhlops تركيبات زنتيكى در مورد سه قطعه از ماهيان كورن

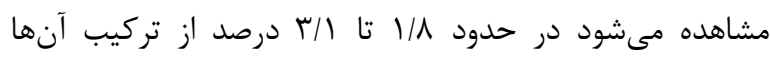

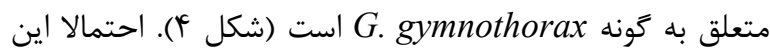




\section{REFERENCES}

Alexander, D.H. \& Lange, K. 2011. Enhancements to the ADMIXTURE algorithm for individual ancestry estimation. BMC Bioinform. 12: 246.

Aljanabi, S.M. \& Martinez, I. 1997. Universal and rapid salt-extraction of high quality genomic DNA for PCRbased techniques. Nucleic Acids Res. 25: 4692-4693.

Benestan, L., Gosselin, T., Perrier, C., Sainte-Marie, B., Rochette, R. \& Bernatchez, L. 2015. RAD genotyping reveals fine-scale genetic structuring and provides powerful population assignment in a widely distributed marine species, the American lobster (Homarus americanus). Mol. Ecol. 24: 3299-3315.

Catchen, J., Hohenlohe, P.A., Bassham, S., Amores, A. \& Cresko, W.A. 2013. Stacks: an analysis tool set for population genomics. Mol. Ecol. 22: 3124-3140.

Coad, B. 2019. Freshwater Fishes of Iran. Available at: www.briancoad.com. Accessed on 14-12-2019.

Decker, J.E., McKay, S.D., Rolf, M.M., Kim, J., Alcalá, A.M., Sonstegard, T.S., Hanotte, O., Götherström, A., Seabury, C.M., Praharani, L. \& Babar, M.E. 2014. Worldwide patterns of ancestry, divergence, and admixture in domesticated cattle. PLOS Genet. 10: p.e1004254.

Dunham, R.A. 2011. Aquaculture and fisheries biotechnology: genetic approaches. Cabi. Oxfordshire, UK, 494 pp.

Farashi, A., Kaboli, M., Rezaei, H.R., Naghavi, M.R., Rahimian, H. \& Coad, B.W. 2014. Reassessment of the taxonomic position of Iranocypris typhlops Bruun \& Kaiser, 1944 (Actinopterygii, Cyprinidae). ZooKeys 374: 69-77.

Hallerman, E.M. 2003. Population genetics: principles and practices for fisheries scientists. American Fisheries Society, Bethesda, MD, 458 pp.

Hashemzadeh Segherloo, I., Abdoli, A., Eagderi, S., Esmaeili, H.R., Sayyadzadeh, G., Bernatchez, L., Hallerman, E., Geiger, M.F., Özulug, M., Laroche, J. \& Freyhof, J. 2017. Dressing down: convergent reduction of the mental disc in Garra (Teleostei: Cyprinidae) in the Middle East. Hydrobiol. 785: 47-59.

Hashemzadeh Segherloo, I., Bernatchez, L., Golzarianpour, K., Abdoli, A., Primmer, C.R. \& Bakhtiary, M. 2012a. Genetic differentiation between two sympatric morphs of the blind Iran cave barb Iranocypris typhlops. J. Fish Biol. 81: 1747-1753.

Hashemzadeh Segherloo, I., Farahmand, H., Abdoli, A., Bernatchez, L., Primmer, C.R., Swatdipong, A., Karami, M. \& Khalili, B. 2012b. Phylogenetic status of brown trout Salmo trutta populations in five rivers from the southern Caspian Sea and two inland lake basins, Iran: a morphogenetic approach. J. Fish Biol. 81: 1479-1500.

Hashemzadeh Segherloo, I., Ghaedrahmati, N. \& Freyhof, J. 2016. Eidinemacheilus, a new generic name for Noemacheilus smithi Greenwood (Teleostei; Nemacheilidae). Zootaxa 4147: 466-476.

Hashemzadeh Segherloo, I., Normandeau, E., Benestan, L., Rougeux, C., Coté, G., Moore, J.S., Ghaedrahmati, N., Abdoli, A. \& Bernatchez, L. 2018. Genetic and morphological support for possible sympatric origin of fish from subterranean habitats. Sci. Rep. 8: 2909.

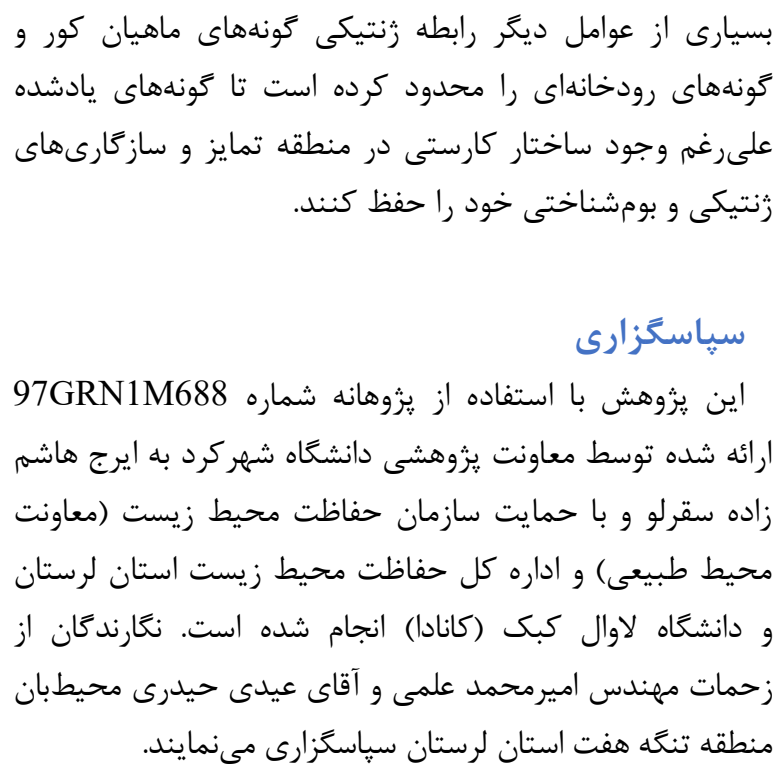


Hubert, N., Hanner, R., Holm, E., Mandrak, N.E., Taylor, E., Burridge, M., Watkinson, D., Dumont, P., Curry, A., Bentzen, P. \& Zhang, J. 2008. Identifying Canadian freshwater fishes through DNA barcodes. PLoS One 3: p.e2490.

Mousavi-Sabet, H. \& Eagderi, S. 2016. Garra lorestanensis, a new cave fish from the Tigris River drainage with remarks on the subterranean fishes in Iran (Teleostei: Cyprinidae). Fish Taxa 1: 45-54.

Proudlove, G.S. 2006. Subterranean fishes of the world: an account of the subterranean (hypogean) fishes described up to 2003 with a bibliography 1541-2004. International Society for Subterranean Biology, 300 pp.

Sargeran, P., Bakhtiyari, M., Abdoli, A., Coad, B.W., Sarvi, K., Lishi, M.R. \& Hajimoradloo, A. 2008. The endemic Iranian Cave-fish, Iranocypris typhlops: two taxa or two forms based on the mental disc? Zool. Middle East 44: 67-74.

Wilkens, H. \& Hüppop, K. 1986. Sympatric speciation in cave fishes? J. Zool. Syst. Evol. Res. 24: 223-230.

How to cite this article:

Hashemzadeh Segherloo, I., Tabatabaei, S.N., Ghaed Rahmati, N., Amiri, M. \& Bernatchez, L. 2020. Analysis of the relationships of Lorestan cave barbs (Garra typhlops and Garra lorestanensis) and Garra gymnothorax populations in Dez and Karkheh River drainages. Nova Bioloica Reperta 7: 1-8. (In Persian).

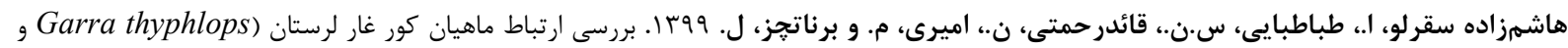

Garra lorestanensis 